\title{
Arthroscopic resection of wrist ganglia
}

\author{
Christophe Mathoulin \\ From 10th Congress of the Asia-Pacific Federation of Societies of Surgery fo the Hand and the 6th Congress \\ of Asia-Pacific Federation of Societies of Hand Therapists \\ Kuala Lumpur, Malaysia. 2-4 October 2014
}

\section{Introduction}

The purpose of this study is to analyse the rate of recurrences of the dorsal ganglion resected by trans-cystic arthroscopic technique. All patients were operated on by a single surgeon with a minimum follow-up of 2 years.

\section{Material and methods}

We report a series of 114 patients with dorsal ganglia ( 87 women and 27 men). The average age was 33.2 years (range:12 to 63 years). All the patients had had an unsuccessful preliminary treatment. Although a minority of patients (32 cases) complained of pain, aesthetic motivation comprised the majority of cases (82 patients).

All the patients were operated under local-regional anaesthesia on an outpatient basis. The shaver was placed directly in trans-cystic, mostly into the midcarpal joint, to perform the capsulectomy and resection of the wall of cyst. The patients were allowed to mobilise their wrist freely immediately post-operatively.

\section{Results}

Our average follow-up was 42.3 months (between 24 and 84 months). The functional clinical data (mobility, pain and strength) were improved in a statistically significant way. We had 14 recurrences $(12 \%)$ which appeared after an average periodof 16.8 months (between 2 and 35 months). The cyst was again removed by wrist arthroscopy in 11 cases at the request of the patients without any particular problem. We had no other complications

\section{Conclusion}

The arthroscopic resection of dorsal ganglia of the wrist is a technique which allows a satisfactory resection of the cyst and the adjacent articular capsule. The rate of recurrence appears significant initially but it is within comparable levels to the best series of classical open

Institut de la Main, 75016, Paris, France 